\title{
Influência da luminosidade e da camada de cera epicuticular de superfícies de folhas de soja na infecção de Phakopsora pachyrhizi
}

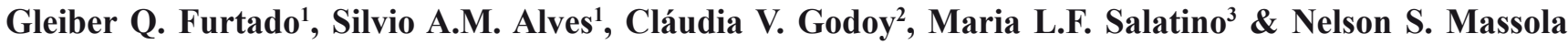 \\ Júnior $^{1}$
}

${ }^{1}$ Departamento de Entomologia, Fitopatologia e Zoologia Agrícola, ESALQ, Universidade de São Paulo, 13418-090, Piracicaba, SP, Brasil; ${ }^{2}$ Embrapa Soja, 86001-970, Londrina, PR, Brasil; ${ }^{3}$ Departamento de Botânica, Instituto de Biociência, Universidade de São Paulo, 05508-900, São Paulo, SP, Brasil

Autor para correspondência: Gleiber Quintão Furtado, e-mail: gleiberfurtado@gmail.com

\begin{abstract}
RESUMO
A ferrugem asiática, causada pelo fungo Phakopsora pachyrhizi, apresenta-se como um dos mais graves problemas fitossanitários da cultura da soja no Brasil, principalmente por não existirem, até o presente momento, cultivares com níveis de resistência satisfatórios. Objetivou-se estudar a influência da luminosidade e da camada de cera das superfícies foliares na infecção de folhas de soja por $P$. pachyrhizi. A superfície adaxial ou abaxial de folíolos do primeiro trifólio de plantas da cultivar BRS 154, estádio fenológico V2, foi inoculada com suspensão de $10^{5}$ urediniósporos $/ \mathrm{mL}^{-1}$. As plantas foram mantidas por 24 horas em câmara úmida e temperatura de $23^{\circ} \mathrm{C}$, sob luz ou escuro, em delineamento fatorial. Posteriormente, permaneceram 14 dias em fotoperíodo de 12 horas, sendo em seguida avaliada a densidade de lesões e a severidade da doença. Em um segundo experimento, avaliou-se in vitro, no escuro e na luz, a porcentagem de germinação de urediniósporos e de formação de apressórios. As camadas de cera adaxial e abaxial dos folíolos foram analisadas quantitativamente (extrações com clorofórmio) e estruturalmente (microscopia eletrônica de varredura). A densidade de lesões e a severidade foram maiores quando se inoculou a superfície adaxial de plantas incubadas no escuro, sem interação significativa entre os fatores. A germinação dos esporos no escuro $(40,7 \%)$ foi significativamente superior à germinação na luz $(28,5 \%)$. O mesmo ocorreu para a formação de apressórios, no escuro $(24,7 \%)$ e na luz $(12,8 \%)$. A quantidade e a estrutura das ceras epicuticulares não apresentaram diferenças entre as duas superfícies.
\end{abstract}

Palavras-chave: interação patógeno-hospedeiro, microscopia eletrônica de varredura, ferrugem asiática da soja.

\begin{abstract}
Influence of light and leaf epicuticular wax layer on Phakopsora pachyrhizi infection in soybean

Asian rust, caused by the fungus Phakopsora pachyrhizi, is one of the most serious phytosanitary problems of soybean in Brazil, especially because no cultivars with satisfactory resistance levels as yet exist. The objective of this study was to evaluate the influence of luminosity and of leaf epicuticular wax on the infection of soybean by P. pachyrhizi. The adaxial and abaxial leaflet surfaces of the first trifoliate leaf from cultivar BRS 154, phenological stage V2, were inoculated with a suspension of $10^{5}$ uredospores $/ \mathrm{mL}$. The plants were kept for 24 hours in a humid chamber at temperature of $23^{\circ} \mathrm{C}$, in light or dark conditions, using a factorial design. Subsequently, the plants were maintained for 14 days under a 12-hour photoperiod. The disease severity and density were evaluated. For in vitro experiments, in light or dark conditions, the evaluation was done in terms of uredospore germination and appressorium formation. The wax content of adaxial and abaxial leaflets was analyzed quantitatively using chloroform extraction and ultrastructurally using scanning electron microscope. Higher density and severity were observed when the adaxial surface was inoculated, with later incubation of the plants in the dark, with no significant interaction between these factors. Spore germination in the dark (40.7\%) was statistically different from spore germination in the light (28.5\%). The same effect was observed with appressorium formation, in the dark (24.7\%) and in the light (12.8\%). The quantity and the ultrastructural aspects of epicuticular wax content did not show differences between the adaxial and abaxial surfaces; nor did they show any effect on infection by Phakopsora pachyrhizi in the soybean cultivar studied.
\end{abstract}

Keywords: pathogen-host interaction, scanning electron microscopy, Asian soybean rust.

\section{INTRODUÇÃO}

A ferrugem asiática da soja, causada pelo fungo basidiomiceto Phakopsora pachyrhizi Syd. \& P. Syd foi relatada pela primeira vez no Japão, em 1903 (Henning, 1903), sendo considerada uma importante doença foliar na África, Asia, Austrália e América do Sul, com danos variando entre 10 a 90\% (Sinclair e Hartman, 1999; Yorinori et al., 2005; Levy, 2005). Além da soja, o fungo pode infectar mais de 60 espécies em 52 gêneros de leguminosas pertencentes à família Fabaceae (Rytter et al., 1984; Ono et al., 1992; Slaminko et al., 2008). 
Os urediniósporos de P. pachyrhizi germinam e penetram diretamente as células epidérmicas e, de forma menos freqüente, células guarda do estômato. Porém, o crescimento do fungo entre as células guarda do estômato, como acontece para a maioria das espécies de fungos causadores de ferrugem, não foi observado (Koch et al., 1983; Bonde et al., 1976; Zambenedetti et al., 2007).

Os processos de germinação e formação de apressório dos urediniósporos, em folhas de plantas de soja ocorrem em torno de 1-2 horas e 2-5 horas após a inoculação, respectivamente, em temperatura de $20^{\circ} \mathrm{C}$ (Bonde et al., 1976). Experimentos conduzidos no Brasil, com a cultivar BRS 154, mostraram que urediniósporos de P. pachyrhizi necessitaram de no mínimo seis horas de água livre para infectar a planta, com faixa de temperatura ideal entre $15 \mathrm{e}$ $25^{\circ} \mathrm{C}$ e temperatura ótima de $23^{\circ} \mathrm{C}$ (Alves et al., 2006).

De acordo com Koch e Hoppe (1987), a luz estimula a germinação de urediniósporos de $P$. pachyrhizi, mas inibe o crescimento do tubo germinativo. Como conseqüência, sob iluminação unidirecional e lateral ao esporo, o tubo germinativo se desenvolve no sentido contrário a luz. A cera epicuticular, como componente da cutícula de diferentes órgãos da planta, apresenta um importante papel durante o processo de pré-penetração de fungos em plantas. Estudos realizados por Marois et al. (1986), Skoropad e Tewari (1977) e Roderick e Thomas (1997) mostraram, respectivamente, um papel importante da cera como barreira física na proteção das bagas de uva ao ataque de Botrytis cinerea, no mecanismo de defesa de canola e mostarda a Alternaria brassicae e também na proteção da superfície abaxial de folhas de centeio ao desenvolvimento de espécies causadoras de ferrugem, Puccinia coronata var. coronata, $P$. graminis subsp. graminicola e P. loliina. A presença de maior quantidade de cera nas folhas pode também dificultar a formação do filme de água necessário para a germinação, conforme observado por Zambenedetti et al. (2007), estudando a reação de genótipos a infecção por P. pachyrhizi. Estudo realizado por Isard et al. (2006) mostra uma ação inibitória da germinação de urediniósporos de $P$. pachyrhizi quando expostos a radiação solar ou ultravioleta. Objetivou-se nesse trabalho estudar a influência da luminosidade e da camada de cera adaxial e abaxial de folíolos de genótipo de soja suscetível na infecção por $P$. pachyrhizi.

\section{MATERIAL E MÉTODOS}

\section{Obtenção e preparo do inóculo}

Os urediniósporos de P. pachyrhizi foram obtidos em plantas de soja com infecção natural oriundas de plantação localizada em Piracicaba, estado de São Paulo, Brasil. A multiplicação dessas estruturas foi realizada por meio de sucessivas inoculações em plantas de soja. As plantas foram inoculadas com suspensão de $10^{5}$ urediniósporos por $\mathrm{mL}$ de água destilada + Tween $20(0,05 \%)$, e mantidas em câmara climatizada com temperatura de $23^{\circ} \mathrm{C}$. A partir de dez dias após a inoculação os esporos foram coletados periodicamente a cada dois dias, sem destacar as folhas, até que estas senecessem. Os esporos foram coletados por meio de leve agitação dos folíolos infectados sobre uma placa de Petri aberta e armazenado em deep freezer, após desidratação em sílica gel por 24 horas (Furtado et al., 2008). Um dia antes da preparação da suspensão de esporos para inoculação, os tubos contendo estas estruturas infectivas foram retirados do deep freezer e submetidos a choque térmico $\left(40^{\circ} \mathrm{C}\right.$ por 1 minuto) e re-hidratação em câmara úmida (16 horas).

\section{Efeito da luz na germinação e formação de apressório}

$\mathrm{O}$ efeito da luminosidade na infecção foi também estudado in vitro. Para isso, foram utilizadas gotas de 30 $\mu \mathrm{L}$ da suspensão de $10^{5}$ urediniósporos sobre placas de Petri de poliestireno com $90 \mathrm{~mm}$ de diâmetro. A posição da gota na placa foi previamente marcada na superfície inferior das placas. Estas foram acondicionadas no interior de caixas "Gerbox" contendo papel germitest umedecido com $20 \mathrm{~mL}$ de água destilada e mantidas em câmara climatizada sob temperatura de $23^{\circ} \mathrm{C}$, na presença ou na ausência de luz. A avaliação das porcentagens de germinação e de formação de apressórios foi realizada contando aleatoriamente 100 urediniósporos por gota de suspensão, em microscópio de luz com aumento de 100x, após 6 horas de incubação. $\mathrm{O}$ desenvolvimento dos tubos germinativos e apressórios foram cessados com adição de $15 \mu \mathrm{L}$ de lactoglicerol sobre cada gota da suspensão e em seguida cobriu-se com lamínula de vidro.

\section{Efeito da luz e superfície foliar na infecção}

Para avaliar a influência da luminosidade e da superfície foliar na infecção de $P$. pachyrhizi utilizaram-se plantas de soja da cultivar BRS 154, no estádio fenológico V2 (Fehr \& Caviness, 1981). A inoculação foi realizada na superfície adaxial ou abaxial do folíolo central do primeiro trifólio da planta de soja. Para garantir que a inoculação alcançasse apenas a superfície alvo, utilizouse um saco plástico para proteger as demais plantas que existiam no vaso. Após a inoculação as plantas foram envoltas em sacos plásticos umedecidos e acondicionadas em câmaras climatizadas com temperatura ajustada para $23^{\circ} \mathrm{C}$. Nas primeiras 24 horas as plantas permaneceram em câmara úmida, na luz ou no escuro. Em seguida as plantas permaneceram sob fotoperíodo de 12 horas de luz por 14 dias. Foram avaliadas a densidade de lesões (número de lesões $/ \mathrm{cm}^{2}$ ) e severidade da doença aos 14 dias após a inoculação, por meio de análise de imagem (Alves et al., 2005).

\section{Caracterização da camada de cera epicuticular}

A caracterização da camada de cera epicuticular adaxial e abaxial, separadamente, de folhas de soja foi realizada por meio da quantificação e visualização de sua organização estrutural. Para isso sementes da cultivar BRS 154 foram semeadas em vasos de alumínio contendo $2 \mathrm{~L}$ da 
mistura de terra, areia e esterco $(2: 1: 2)$ e mantidos em casa de vegetação. Utilizaram-se como amostras os primeiros trifólios de plantas no estádio fenológico V2 (Fehr \& Caviness, 1981).

Para a quantificação da cera das superfícies foliares foram utilizadas dez repetições por superfície, cada repetição consistiu de um trifólio (primeiro trifólio). As extrações químicas foram realizadas no Laboratório de Fitoquímica do Instituto de Biociências da Universidade de São Paulo, São Paulo, SP. A extração da cera de cada trifólio foi realizada utilizando-se o volume de $9 \mathrm{~mL}$ de clorofórmio, sendo $3 \mathrm{~mL}$ para cada folíolo. A lavagem das superfícies foi realizada com auxilio de pipeta Pauster, em capela de exaustão, sendo o volume de clorofórmio aplicado, cuidadosamente, em toda a superfície foliar. Posteriormente, o extrator e a cera removida foram filtrados em filtro de papel, previamente lavados em clorofórmio. O filtrado, obtido em balão volumétrico, sofreu evaporação por aquecimento, sob pressão reduzida em rota-evaporador. Após a evaporação do clorofórmio, o balão volumétrico foi lavado três vezes com clorofórmio para remoção total da cera, e o conteúdo transferido para pequeno frasco de vidro, previamente pesado, e levados para evaporação em capela de exaustão. Após a completa evaporação, os recipientes foram transferidos para dessecador até atingirem peso constante. $\mathrm{O}$ teor de cera foi determinado em função da área do folíolo. A área foliar foi obtida por meio de fotografia digital e análise de imagem utilizando o software Quant (Vale et al., 2002).

\section{Análise de ultra-estrutura}

As análises de ultra-estrutura foram realizadas no Núcleo de Microscopia Eletrônica Aplicada a Pesquisa Agropecuária da Escola Superior de Agricultura "Luiz de Queiroz", Piracicaba, SP. A técnica de microscopia eletrônica de varredura (MEV) foi utilizada para visualização da organização estrutural da camada de cera epicuticular de ambas as superfícies dos folíolos de plantas de soja. Para essas observações da camada de cera em relação à superfície foliar, coletaram-se duas amostras por superfície de cada folíolo central do primeiro trifólio de soja. As amostras foram fixadas por 12 horas em vapor de ósmio (Kitajima \& Leite, 1999) e, posteriormente, transferidas para um recipiente com sílica gel, onde permaneceram por
24 horas. As amostras, seis de cada superfície foliar, foram aderidas a suportes de alumínio (stubs) com fita de carbono e metalizadas com vapor de ouro em aparelho MED 010 (Balzers, Lichtenstein) a $50 \mathrm{~mA}$ por 180 s. A observação foi realizada em Microscópio Eletrônico de Varredura Zeiss modelo DMS 940A (Zeiss, Germany).

\section{Delineamento experimental e análise de dados}

Para avaliar o efeito da luz e da superfície foliar na infecção de soja por $P$. pachyrhizi, o experimento foi montado em delineamento inteiramente casualizado, em esquema fatorial 2 (superfícies adaxial e abaxial) x 2 (luz e escuro), com quatro repetições. Cada repetição consistiu em um vaso com três plantas. $\mathrm{O}$ efeito da luminosidade na germinação e formação de apressórios in vitro foi avaliado em delineamento inteiramente casualizado, com cinco repetições por tratamento. Cada repetição consistiu em uma placa de Petri contendo três gotas da suspensão de esporos. Os experimentos acima foram feitos em duplicatas. Os dados de cada experimento foram analisados isoladamente pela ANOVA e teste de média, Tukey $(\mathrm{P}<0,05)$. Os valores apresentados se referem à média resultante da combinação dos dois experimentos, pois ambos não se diferenciaram significativamente pelo teste t. Portanto, para o primeiro e o segundo estudo, os valores se referem à média de oito repetições e dez repetições, respectivamente.

\section{RESULTADOS}

O fungo $P$. pachyrhizi mostrou-se apto a infectar folhas de soja tanto na luz quanto no escuro (Tabela 1). A interação fatorial não foi estatisticamente significativa para os fatores luminosidade e superfície foliar inoculada. Com relação à superfície foliar, observaram-se valores estatisticamente superiores de intensidade de doença quando a inoculação foi realizada na superfície adaxial, tanto para a severidade quanto para a densidade de lesões. No escuro, as severidades observadas para inoculações na superfície adaxial e abaxial foram $24,4 \%$ e $17,4 \%$, respectivamente. Já na presença de luz, a severidade, quando se inoculou a superfície adaxial foi $15,9 \%$ e abaxial 10,2\%. A densidade de lesões de $P$. pachyrhizi no escuro foi 99,9 e 77,3 lesões/ $\mathrm{cm}^{2}$ para inoculações realizadas na superfície adaxial e abaxial, respectivamente. $\mathrm{Na}$ luz também se observou

TABELA 1 - Influência da luminosidade (claro e escuro) e da superfície (adaxial e abaxial) na severidade (\%) e densidade de lesões $\left(\right.$ lesões $\left./ \mathrm{cm}^{2}\right)$ de ferrugem da soja em folhas do cultivar BRS 154

\begin{tabular}{|c|c|c|c|c|c|c|}
\hline & \multicolumn{3}{|c|}{ Severidade* } & \multicolumn{3}{|c|}{ Densidade de les ões } \\
\hline & Claro & Escuro & Média & Claro & Escuro & Média \\
\hline Adaxial & 15,9 & 24,4 & $20,2 \mathrm{~A}$ & 57,7 & 99,9 & $78,8 \mathrm{~A}$ \\
\hline Abaxial & 10,2 & 17,4 & $13,8 \mathrm{~B}$ & 41,0 & 77,3 & $59,1 \mathrm{~B}$ \\
\hline Média & $13,1 \mathrm{~b}$ & 20,9 a & & $49,3 \mathrm{~b}$ & 88,6 a & \\
\hline
\end{tabular}

*Médias seguidas da mesma letra maiúscula na coluna e minúscula na linha não diferem estatisticamente pelo teste de Tukey $(\mathrm{P}<0,05)$. 
maior valor ao inocular a superfície adaxial (57,7 lesões/ $\left.\mathrm{cm}^{2}\right)$ em relação à abaxial $\left(41,0\right.$ lesões $\left./ \mathrm{cm}^{2}\right)$. Apesar de P. pachyrhizi ter causado infecção em todas as condições testadas, os resultados mostraram intensidade de doença estatisticamente superior quando a inoculação foi realizada na superfície adaxial e a incubação realizada no escuro.

Com relação ao fator luminosidade, a condição de escuro mostrou-se mais favorável que a luz para o desenvolvimento das estruturas infectivas in vitro (Figura 1). A porcentagem de germinação dos esporos no escuro $(40,7 \%)$ foi estatisticamente diferente da germinação na luz $(28,5 \%)$. O mesmo ocorreu para a formação de apressórios, no escuro $(24,7 \%)$ e na luz $(12,8 \%)$. Os apressórios desenvolvidos sob luz apresentaram tamanho visualmente menores quando comparados àqueles que tiveram seu desenvolvimento no escuro (Figura 2).

O teor de cera obtido das superfícies foliares de soja não foi significativamente diferente (Figura 3). Diferenças visuais também não foram observadas pelas análises de microscopia eletrônica de varredura que avaliou a organização estrutural das ceras em ambas as superfícies foliares (Figuras 4).

\section{DISCUSSÃO}

$\mathrm{O}$ experimento realizado in vitro confirmou a capacidade dos urediniósporos de $P$. pachyrhizi de germinarem e formarem apressórios quando incubados tanto no escuro quanto na luz, com maiores taxas no escuro (Figura 1). Estes resultados corroboram as observações de maiores níveis de ferrugem quando se incubou, após a inoculação, as plantas no escuro (Tabela 1). Além disso, a maioria dos apressórios desenvolvidos sob luz apresentou tamanho aparentemente reduzido quando comparados àqueles que tiveram seu desenvolvimento no escuro (Figura 2), sendo mais um indício da sensibilidade desse fungo à luz.

Koch \& Hoppe (1987) observaram in vitro que as taxas de germinação de urediniósporos de $P$. pachyrhizi não foram significativamente afetadas pela luz. Porém, a emergência e desenvolvimento do tubo germinativo, submetidos à iluminação policromática unidirecional, ocorreu a partir do lado do esporo sombreado. Ainda, a iluminação não interferiu na germinação, mas inibiu o desenvolvimento do tubo germinativo, sendo a luz azul a responsável por esse fototropismo. A inibição da germinação de urediniósporos, sob luz branca, foi observada também para alguns fungos causadores de ferrugem em cereais. Alta intensidade desta luz inibiu completamente a germinação de Puccinia graminis f.sp. tritici (Givan \& Bromfield, 1964a., Lucas et al., 1975) e Puccinia recondita f.sp. tritici (Givan \& Bromfield, 1964b). A incubação de plantas de eucalipto inoculadas com urediniósporos de Puccinia psidii Winter na presença de luz mostrou ser desfavorável também à germinação e à infecção desse fungo (Ruiz et al., 1989).
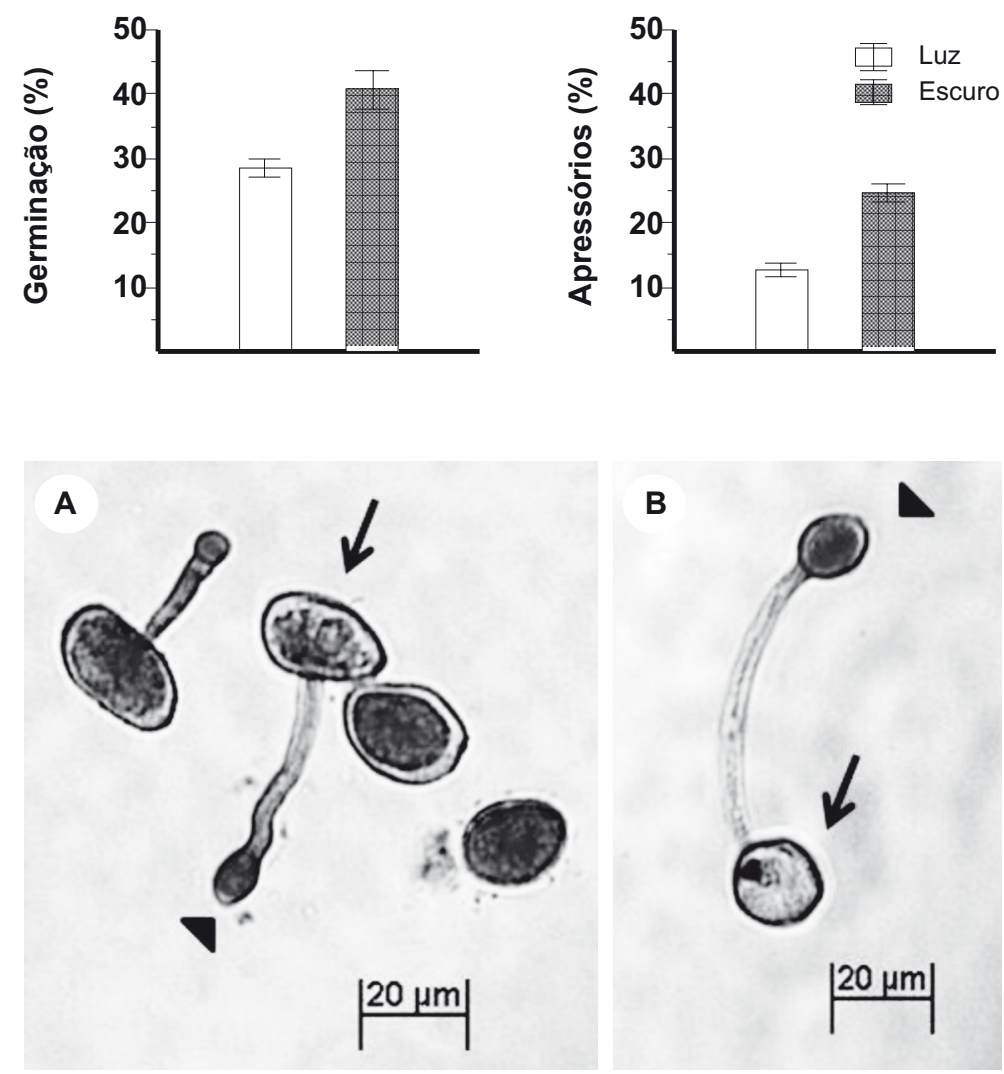

FIGURA 1 - Porcentagem de germinação e formação de apressórios de urediniósporos de $P$. pachyrhizi in vitro, em função da luminosidade. Os tratamentos com letras diferentes diferem estatisticamente pelo teste de Tukey $(\mathrm{P}<0,05)$. Barra de erro representa erro padrão da média.
FIGURA 2 - Germinação de urediniósporos (seta) de P. pachyrhizi e formação de apressório (ponta de seta) sob luz (A) e escuro (B). 


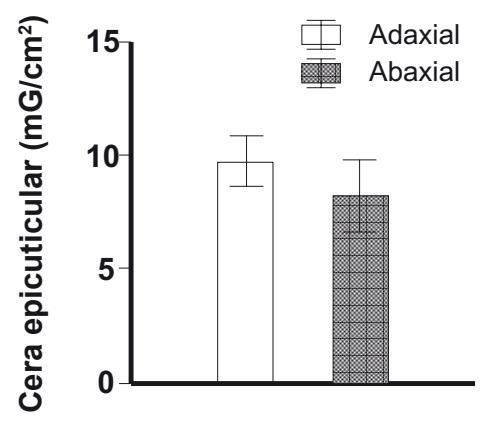

FIGURA 3 - Teor de cera epicuticular da superfície adaxial e abaxial de folhas de soja do cultivar BRS 154. Barra de erro representa erro padrão da média.
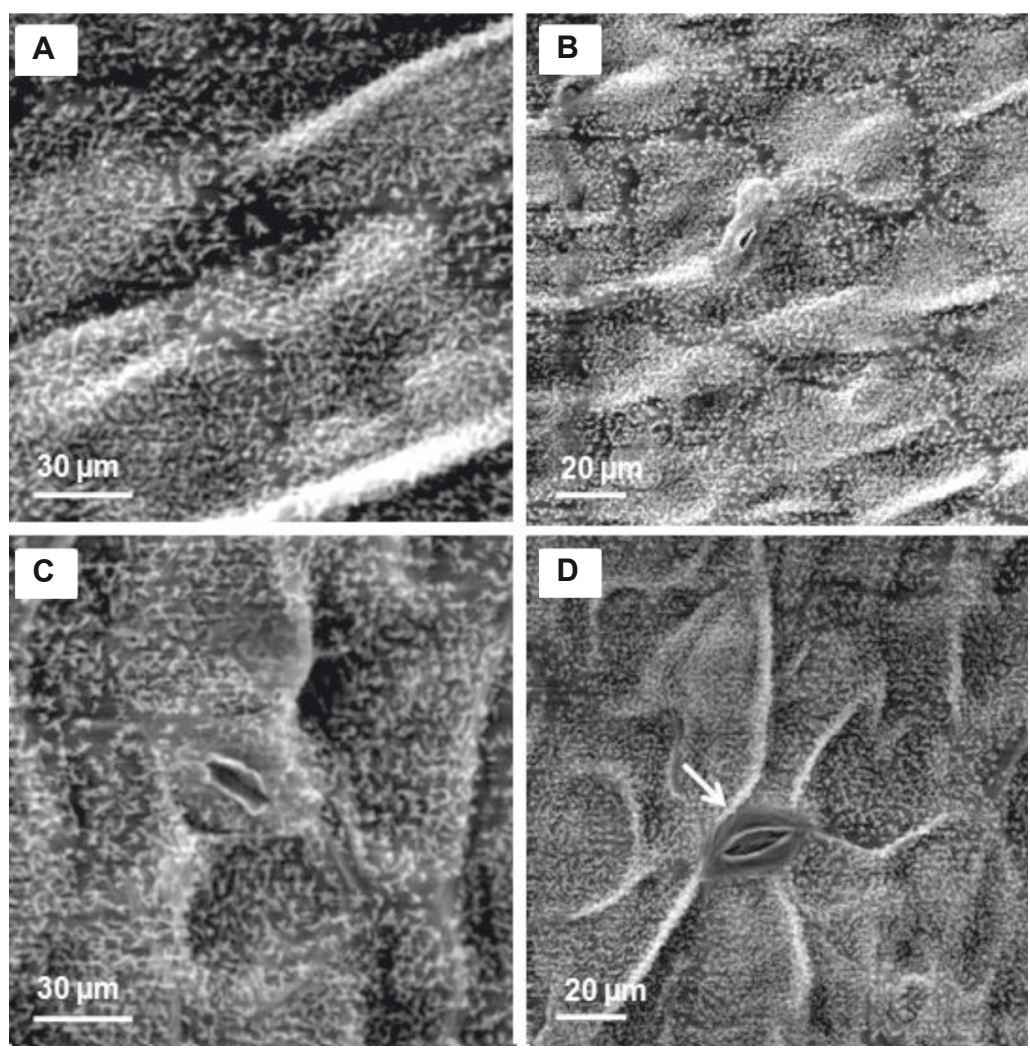

FIGURA 4 - Imagens de microscopia eletrônica de varredura do aspecto da estrutura da camada de cera epicuticular da superfície adaxial (A-B) e abaxial (CD) de folhas de soja do cultivar BRS 154. Seta apontando estômato.

O efeito negativo da luz na infecção de $P$. pachyrhizi, observado nesse trabalho, corrobora os resultados obtidos por Isard et al. (2006) que observaram efeito deletério da radiação solar e ultravioleta na germinação de urediniósporos. Este efeito negativo da radiação juntamente a maior suscetibilidade de folhas mais velhas demonstrada por Furtado et al. (2009) podem ser responsáveis pelo desenvolvimento da ferrugem no sentido base-ápice das plantas de soja, em condições de campo. Além de se ter com o fechamento das entrelinhas um microclima mais favorável à doença no dossel inferior da cultura.

Com relação à cera epicuticular, não houve diferenças evidentes entre a superfície adaxial e abaxial das folhas de soja de tal forma que pudessem explicar as diferenças observadas na infecção de $P$. pachyrhizi, diferença esta já constatada em outros patossistemas. No trabalho de Carver et al. (1990) foi demonstrada a influência da organização da camada de cera na infecção do patógeno biotrófico Erysiphe graminis em centeio. Folhas de centeio 
e aveia foram inoculadas na superfície adaxial e abaxial e apenas na superfície abaxial de centeio o crescimento e o desenvolvimento normal do tubo germinativo foi impedido. Por meio de microscopia eletrônica de varredura ficou demonstrado que a cera epicuticular desta superfície apresentava aspecto amorfo, enquanto na superfície adaxial e em ambas as superfícies das folhas de aveia a camada de cera apresentou um aspecto cristalino. Após a remoção, com clorofórmio, da cera abaxial das folhas de centeio, conídios de E. graminis foram inoculados e tiveram o desenvolvimento do tubo germinativo normalizado.

A camada de cera amorfa da superfície abaxial das folhas de centeio, juntamente com o pequeno número de estômatos, impediu o desenvolvimento de espécies causadoras de ferrugem, tais como Puccinia coronata, $P$. graminis e $P$. loliina. Entretanto, quando os urediniósporos dessas ferrugens foram inoculados na superfície adaxial, os tubos germinativos apresentaram desenvolvimento e crescimento normal, direcional aos estômatos, o que provavelmente se deve à organização cristalina da camada de cera desta face foliar (Roderick \& Thomas, 1997). A intensidade diferencial da ferrugem observado nas superfícies foliares não se correlacionou com as características da cera epicuticular. Os menores valores de densidade de lesões na superfície abaxial, possivelmente, são decorrentes de barreiras existentes posteriormente ao processo de pré-penetração.

A metodologia proposta no presente trabalho para qualificar e quantificar a camada de cera epicuticular de folhas de soja por meio, respectivamente, de microscopia eletrônica de varredura e extrações com clorofórmio se mostrou adequada. Portanto, com esse estudo não se elimina a possibilidade da camada de cera comportar como uma barreira à penetração de $P$. pachyrhizi, sendo necessária a realização de novos estudos envolvendo diferentes cultivares para o melhor entendimento do papel desse componente na resistência de folhas de soja a esse fungo.

\section{REFERÊNCIAS BIBLIOGRÁFICAS}

Alves SAM, Carneiro LC, Furtado GQ, Bergamin Filho A (2005) Método preciso para quantificação de ferrugem asiática da soja. Fitopatologia Brasileira 30S:132.

Alves SAM, Furtado GQ, Bergamin Filho A (2006) Influência das condições climáticas sobre a ferrugem da soja. In: Zambolim L (Ed.) Ferrugem asiática da soja. Viçosa MG. Universidade Federal de Viçosa. pp. 15-32.

Bonde MR, Melching JS, Bromfield KR (1976) Histology of the suscept-pathogen relationship between Glycine max and Phakopsora pachyrhizi. Phytopathology 66:1290-1294.

Carver TL, Thomas BJ, Ingerson-Morris SM, Roderick HW (1990) The role of the abaxial leaf surface waxes of Lolium spp. in resistance to Erysiphe graminis. Plant Pathology 39:573-583.
Fehr WR, Caviness CE (1981) Stages of soybean development. Iowa State University. Special Report 80.

Furtado GQ, Alves SAM, Czermainski ABC, Massola Júnior NS (2008) Preservation of uredospores Phakopsora pachyrhizi. Journal of Phytopathology 156:62-64.

Furtado GQ, Alves SAM, Godoy, CV, Carneiro LC, Massola Júnior NS (2008) Influência do estádio fenológico e da idade dos trifólios de soja na infecção de Phakopsora pachyrhizi. Tropical Plant Pathology 34:118-122.

Givan CV, Bromfield KR (1964a) Light inhibition of uredospores germination in Puccinia graminis var. tritici. Phytopathology 54:382-384.

Givan CV, Bromfield KR (1964b) Light inhibition of uredospores germination in Puccinia recondita. Phytopathology 54:116-117.

Hennings VP (1903) A few new Japanese Uredinaceae. Hedwigia 42:107-108.

Isard SA, Dufault NS, Miles MR, Hartman GL, Russo JM, De Wolf ED, Morel W (2006) The effect of solar irradiance on the mortality of Phakopsora pachyrhizi urediniospores. Plant Disease 90:941-945.

Kitajima EW, Leite B (1999) Curso introdutório de microscopia eletrônica de varredura. 2.ed. Piracicaba SP. NAP/MEPA. ESALQ, Universidade de São Paulo.

Koch E, Ebrahim-Nesbat F, Hoppe HH (1983) Light and electron microscopic studies on the development of soybean rust (Phakopsora pachyrhizi Syd.) in susceptible soybean leaves. Phytopathologische Zeitschrift 106:302-320.

Koch E, Hoppe HH (1987) Effect of light on uredospore germination and germ tube growth of soybean rust (Phakopsora pachyhrizi Syd.). Journal of Phytopathology 119:64-74.

Levy C (2005) Epidemiology and chemical control of soybean rust in southern Africa. Plant Disease 89:669-674.

Lucas JA, Kendrick RE, Givan CV (1975) Photocontrol of fungal spore germination. Plant Physiology 56:847-849.

Marois JJ, Nelson JK, Morrinson JC, Lile LS, Bledsoe AM (1986) The influence of berry contact within grape clusters on the development of Botrytis cinerea and epicuticular wax. American Journal of Enology and Viticulture 37:293-296.

Ono Y, Butirica P, Hennen JF (1992) Delimination of Phakopsora, Physopella and Cerotelium and their species on leguminosae. Mycological Research 96:825-850.

Roderick HW, Thomas BJ (1997) Infection of ryegrass by three rust fungi (Puccinia coronata, P. graminis and P. loliina) and some effects of temperature on the establishment of the disease and sporulation. Plant Pathology 46:751-761.

Ruiz RAR, Alfenas AC, Ferreira FA, Ribeiro do Vale FX (1989) Influência da temperatura, do tempo de molhamento foliar, fotoperíodo e da intensidade de luz sobre a infecção de Puccinia psidii em eucalipto. Fitopatologia Brasileira 14:51-57.

Rytter JL, Dowler WM, Bromfield KR (1984) Additional alternative hosts of Phakopsora pachyrhizi, causal agent of soybean rust. Plant Disease 68:818-819.

Sinclair JB, Hartman GL (1999) Soybean rust. In: Hartman GL, Sinclair JB, Rupe JC (Eds.) Compendium of soybean diseases. Saint Paul MN. APS Press. pp. 3-4. 
Skoropad WP, Tewari JP (1977) Field evaluation of the role of epicuticular wax in rapeseed and mustard in resistance to Alternaria blackspot. Canadian Journal of Plant Science 57:1001-1003.

Slaminko TL, Miles MR, Frederick RD, Bonde MR, Hartman GL (2008) New legume hosts of Phakopsora pachyrhizi based on greenhouse evaluations. Plant Disease 92:767-771.

Vale FXR, Fernandes Filho EI, Liberato JR, Zambolim L (2001) Quant - a software to quantify plant disease severity. Proceedings of the 8th International Workshop on Plant Disease Epidemiology. Ouro Preto MG.
Yorinori JT, Paiva WM, Frederick RD, Costamilan LM, Bertagnolli PF, Hartman GL, Godoy CV, Nunes Junior J (2005) Epidemics of soybean rust (Phakopsora pachyrhizi) in Brazil and Paraguay from 2001 to 2003. Plant Disease 89:675-677.

Zambenedetti EB, Alves E, Araújo DV (2007) Eventos dos processos de pre-penetração, penetração e colonização de Phakopsora pachyrhizi em folíolos de soja. Fitopatologia Brasileira 31:156-160.

TPP 9046 - Recebido 6 Abril 2009 - Aceito 22 Outubro 2009 Editor de Seção - convidado: Emerson Del Ponte 